\title{
РОЛЬ ИНФОРМАЦИОННО-КОММУНИКАЦИОННЫХ ТЕХНОЛОГИЙ В ОБЕСПЕЧЕНИИ КАЧЕСТВА ПРЕПОДАВАНИЯ В ВЫСШИХ УЧЕБНЫХ ЗАВЕДЕНИЯХ
}

\section{THE ROLE OF INFORMATION AND COMMUNICATION TECHNOLOGIES IN ENSURING THE QUALITY OF TEACHING IN HIGHER EDUCATION INSTITUTIONS \\ A. Kuldybayev \\ S. Amirkhanov \\ A. Ixanov}

Summary: The article deals with information and communication technologies and their role in modern education, in particular, in teaching in higher educational institutions. The widespread development and dissemination of information and communication technologies has a significant impact on human life, but the methods and approaches of their application in the learning process require additional consideration. Objective: to identify the role of information and communication technologies in ensuring the quality of teaching in higher education institutions.

Methods: theoretical analysis of scientific and pedagogical literature, synthesis, generalization.

Results: success in ensuring the quality of teaching in higher education institutions is primarily determined by the level of implementation of modern teaching methods.

Conclusions: during the analysis of the specialized literature, it was revealed that in the field of organization and management of the learning process in higher educational institutions, there are a number of problems. This is due to the fact that the methodology of research in pedagogy has long been formed on traditional teaching methods.

Keywords: information and communication technologies; pedagogy; zoom platform; student education; higher education.
Кулдыбаев Айбек Кайрсапиевич

Преподаватель, Западно-Казахстанский аграрно-технический университет имени Жангир хана zkatu.zhangirhan@yandex.ru

Амирханов Саяхат Мухамбетулы

Преподаватель, Западно-Казахстанский аграрно-технический университет имени Жангир хана Иксанов Адилкан Серикович

Преподаватель, Западно-Казахстанский аграрно-технический университет имени Жангир хана

\section{Аннотация:}

B статье рассматриваются информационно-коммуникационные технологии и их роль в современном образовании, в частности, в преподавании в высших учебных заведениях. Широкое развитие и распространение информационно-коммуникационных технологий оказывает значительное влияние на жизнедеятельность человека, однако методы и подходы их применения в процессе обучения требуют дополнительного рассмотрения.

Цель: выявление роли информационно-коммуникационных технологий в обеспечении качества преподавания в высших учебных заведениях.

Методы: теоретический анализ научно-педагогической литературы, синтез, обобщение.

Результаты: успешность в обеспечении качества преподавания в высших учебных заведениях, в первую очередь, определяется уровнем внедрения современных методов обучения.

Выводы: в ходе анализа специальной литературы, было выявлено, что в области организации и управления процессом обучения в высших учебных заведениях существует целый ряд проблем. Это обусловлено тем, что методология исследований в педагогике долгое время формировалась на традиционных методах преподавания.

Ключевые слова: информационно-коммуникационные технологии; педагогика; платформа zoom; обучение студентов; высшее образование.

и др. Кроме того, вопросу повышения профессиональной компетентности педагогов уделяется значительное внимание, так как данная дисциплина требует внедрения особых методов и подходов использования информационных технологий в процессе обучения. Совершенствование работы преподавателей высших учебных заведений возможно на основе использования информационно-коммуникационных технологий (ИКТ), однако специфика высшего образования заключается в том, что в отличии от других, она не может переходить на дистанционный уровень полностью, так как ее важнейшей составной частью является и практическая деятельность студентов. Поэтому роль педагога в данной деятельности велика. 
Модернизация системы образования должна создать условия для обучения молодого поколения в информационно-технологическом обществе XXI века, где определяющим фактором является уровень личного образования, его интеллектуальный и творческий потенциал, который позволяет использовать и разрабатывать новые методы в науке и производстве.

\section{^итературный обзор}

Согласно исследованиям О.А. Ильченко, одной задачей модернизации и информатизации современного образования, является создание информационно-образовательной среды обучения, направленной на повышение качества образования [4].

Перейдем к более подробному рассмотрению понятия информационно-коммуникационных технологий (ИКТ).

Информационные технологии (ИТ) представляют собой совокупность систематических и массовых методов, а также методов обработки информации, созданных прикладной информатикой во всех видах человеческой деятельности с использованием современных средств связи, полиграфии, компьютерных средств и программного обеспечения. В процессе преподавания дисциплин с использованием компьютеров, они имеют первостепенное значение. Например, дисциплина «Компьютерная графика», преподавание которое невозможно без компьютера. Однако, существует множество других дисциплин, где применение современных инновационных методов обучения пока не вышло на должный уровень. Например, при преподавании дисциплины «Безопасность техники и технологии» или «Транспортная логистика» преобладают традиционные формы обучения.

Совокупность информационных и образовательных технологий представляет собой технологии в сфере образования, которые используют специальные технические информационные инструменты (компьютер, аудио, кино, видео) для достижения педагогических целей. По словам И.Н. Мовчан, информационно-образовательная среда любого образовательного учреждения обязана включать в себя наиболее полный комплекс информационно образовательных ресурсов, в число которых входят: цифровые образовательные ресурсы, компьютеры и иное оборудование, современная система разработанных педагогических технологий, коммуникационные каналы связи и др. [7].

Использование информационных компьютерных технологий (ИКТ) в образовании имеет ряд преимуществ:

1. Информационные технологии значительно расширяют возможности для представления обра- зовательной информации. Использование цвета, графики, звука, всего современного видеооборудования позволяет воссоздать реальную ситуацию. Так, например, при преподавании дисциплины «Транспортная логистика», важнейшим аспектом является визуализация изучаемых объектов;

2. Пользование современными технологии может значительно повысить уровень мотивации учащихся к обучению. Адекватная оценка познавательных способностей учащихся, позволяет объективно оценить способности и наметить наиболее оптимальные цели в обучении;

3. ИКТ привлекают учащихся к процессу обучения, способствуют широкому раскрытию их способностей, активизации познавательной деятельности;

4. Использование ИКТ в учебном процессе увеличивает возможности для задания учебных задач и управления процессом их решения. Компьютеры позволяют создавать и анализировать модели различных объектов, ситуаций, явлений;

5. ИКТ позволяют осуществить наиболее объективный контроль над деятельностью учащихся, обеспечивая при этом гибкость управления процессом обучения. Подобный контроль способствует формированию рефлексии учащихся.

На основе использования ИКТ в процессе обучения информационная функция педагога перестает быть ключевой. Со стороны учителя, на первый план выходит организационная и контрольная функции.

Психолого-педагогические основы использования ИКТ в обучении - это концепции обучения развитию, подхода к деятельности и технологии исследовательской деятельности. Таким образом, основная роль учителя заключается в определении целей обучения, организации условий, необходимых для успешного решения образовательных проблем.

На сегодняшний день, важной задачей становления и развития информационно - образовательной среды является то, что данный ресурс должен отражать приоритетность образовательных педагогических целей по отношению к внедряемым информационно-коммуникационным технологиям в систему образования. Здесь наиболее точным является высказывание Е.В. Мельниковой и П.В. Веденеева, представляющих информационно-образовательную среду, как систему психолого-педагогических условий и программно-аппаратных средств, способствующих непосредственно информационному взаимодействию между субъектами образовательного процесса. [6] Соответственно, подобная формулировка предполагает разнообразное содержание рассматриваемого нами понятия, видение его как сложной системы, 
состоящей из множества отдельных частей, взаимодействующих между собой. Существуют следующие ключевые компоненты информационно-образовательной среды:

а) ценностно-целевой компонент, отражающий совокупность целей и перечень ценностей педагогического образования;

б) содержательно-методический компонент, направленный на содержательную сферу данной среды, отражающий методы и принципы обучения;

В) коммуникационно-психологический компонент, определяющий особенности субъектов в процессе обучения;

г) организационно-административный компонент, отображающий правовую основу, совокупность нормативной документации [4].

Определение оптимальных условий использования ИКТ для активизации процесса обучения, повышения его эффективности и качества, является существенным. Такая дисциплина, как «Безопасность техники и технологии», основанная на развитии умений и навыков обеспечения нормального состояния окружающей человека среды, условий труда и учёбы, питания и отдыха, при которых снижена возможность возникновения опасных факторов, угрожающих его здоровью, жизни, имуществу. Применение ИКТ при занятиях данной дисциплины должно быть в комплексе с традиционными методами. Одним из оптимальных средств организации занятий может являться платформа ZOOM. Это облачная платформа для проведения онлайн видео-конференций и видео-вебинаров в формате высокой четкости, что позволяет дистанционно обучать студентов, разделять их а группы, рассылать как групповые, так и индивидуальные задания. Каждое учебное занятие представляет собой единицу процесса обучения. В зависимости от сочетания методов и средств обучения, различают занятия как комплексной, так и избирательной направленности.

\section{Выводы}

В ходе анализа специальной литературы, было выявлено, что в области организации и управления процес- сом обучения в высших учебных заведениях существует целый ряд проблем. Это обусловлено тем, что методология исследований в педагогике долгое время формировалась на традиционных методах преподавания.

Успешность в обеспечении качества преподавания в высших учебных заведениях, в первую очередь, определяется уровнем внедрения современных методов обучения.

Необходимо отметить, что в научно-методической литературе методология с использованием ИКТ является недостаточно разработанной. Имеются лишь единичные работы, освещающие отдельные стороны ИКТ и их роли в образовательном процессе.

\section{Зак^ючение}

Применение ИКТ на таких дисциплинах, как, например, «Безопасность техники и технологии», «Компьютерная графика», позволит сэкономить время учителя на объяснение материала. Так, например, демонстрация правильного выполнения упражнений посредством видео, позволит наглядно продемонстрировать его технические особенности, выделить ошибки, предупредить о возможных сложностях и т.д.

Известно, что современное молодое поколение испытывает повышенный интерес к технологиям, транспорту. Таким образом, использование наглядных материалов (видео-контента) в процессе преподавания, например, дисциплины «Транспортная логистика», позволит повысить интерес учащихся к данной дисциплине.

Директор Института информатизации образования РАО И.В. Роберт подчеркивает возможности использования ИКТ, «реализация которых создает предпосылки для беспрецедентной в истории педагогики интенсификации учебного процесса, а также создания методов, направленных на развитие личности обучаемого». На сегодняшний день, ИКТ вносят колоссальный вклад в создание наиболее эффективного процесса обучения, обеспечивают занятость учащихся, рост знаний, способствуют обретению дополнительных навыков обучения [4].

\section{ЛИТЕРАТУРА}

1. Jesus Lau, Guidelines on Information Literacy for Lifelong Learning// http://www.uv.mx/usbiver/

2. Strzebkowski, R. (2017)/ Realisierung von Interaktivitaet und multimedialen Praesentationstechniken In L. I. Issing \& P. Klimsa (Hrsg.), Information und Lernen mit Multimedia. Weinheim: Psychologie Verlags Union). S. 269-304.

3. Андреев А.А., Солдаткин В.И. Дистанционное обучение: Сущность, технология, организация. — М.: МЭСИ, 1999.

4. Ильченко 0.А. Стандартизация новых образовательных технологий // Высшее образование в России. 2006. № 4 С. 101-130 
5. Кузьмина Н.В. Методы системного педагогического исследования. Л.: ЛГу, 1980. 10 с.

6. Мельникова Е.В. Формирование образовательной информационной среды школы как средства повышения качества учебных достижений учащихся. Иваново, 2006, С. 7

7. Мовчан И.Н. Цифровые образовательные ресурсы: современные возможности и тенденции развития//Сборник научных трудов Sworld. 2010. T. 26. №4. C. $36-38$

с Кулдыбаев Айбек Кайрсапиевич (zkatu.zhangirhan@yandex.ru ), Амирханов Саяхат Мухамбетулы, Иксанов Адилкан Серикович.

Журнал «Современная наука: актуальные проблемы теории и практики»

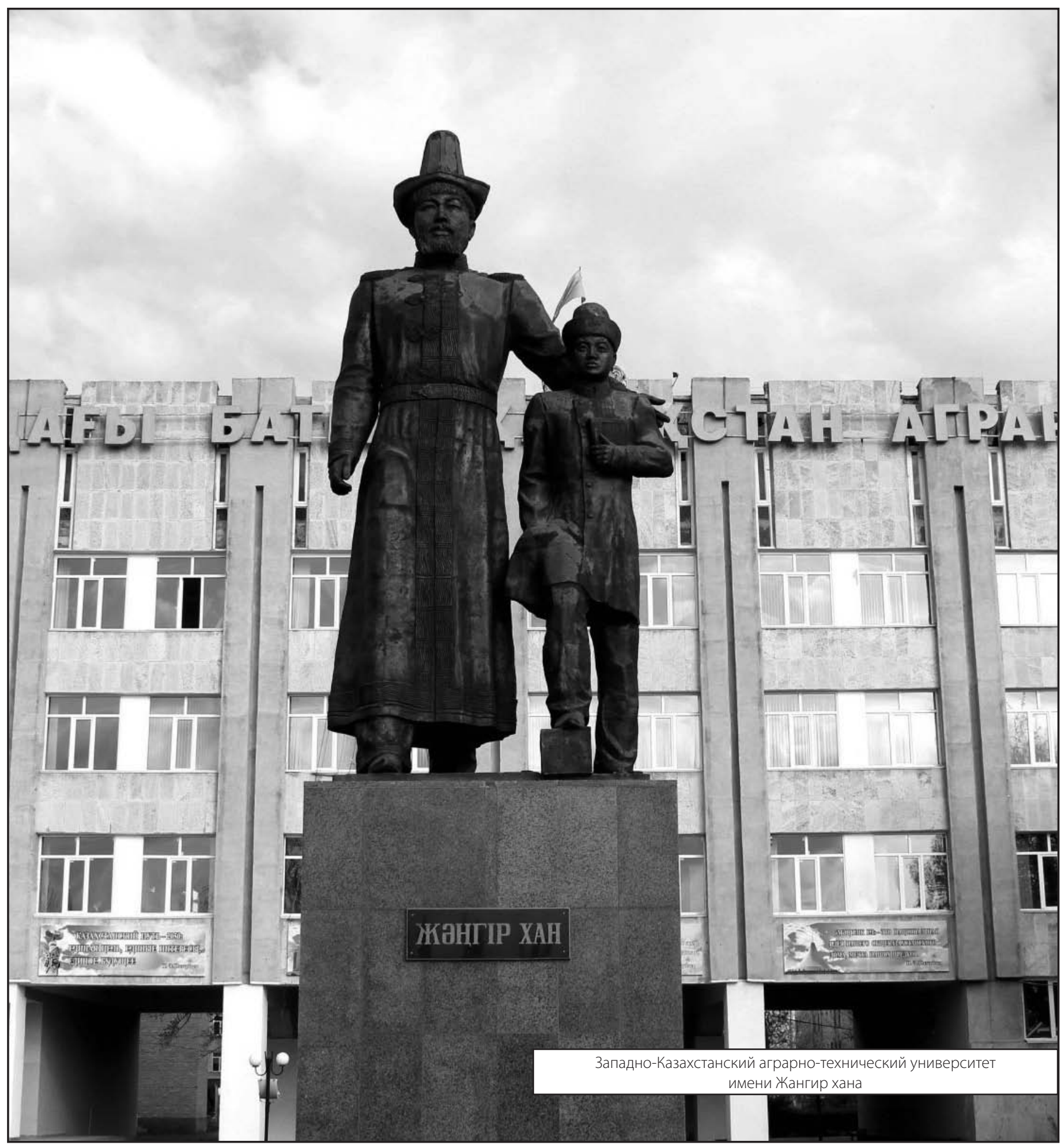

